\title{
To end ambiguous sentences
}

A study of the time required to complete ambiguous sentences suggested that: even though $S$ s are unaware of the ambiguity while completing sentences, they take more time to complete ambiguous sentences than unambiguous ones: the degree of difficulty in completing ambiguous sentences is related to the linguistic level at which the ambiguity occurs: sentences containing two ambiguities are more difficult to complete than those containing only one, and when these two ambiguities occur at different linguistic levels, these sentences are harder to complete than when both occur within the same linguistic level: ambiguity may affect the grammaticality and relevance of completions; and may cause stuttering and laughter, even without awareness of the ambiguity. An attempt to fit these results to several theories of the processing of ambiguous sentences led us to the conclusion that ambiguity interferes with our understanding of a single meaning of a sentence, and that the degree of interference varies with the linguistic level at which the ambiguity occurs.

\section{INTROQUCTION}

As one of the two meanings of the title suggests, this paper deals with the completion of ambiguous sentences. These are some of the general questions which motivated this study: Are subjects normally aware of ambiguity in processing and producing ambiguous sentences? Do ambiguous sentences take longer to complete than similar but unambiguous ones? Do subjects tend to use more words for the completion of ambiguous sentences than unambiguous ones? Do they tend to eliminate ambiguity in their completion? Does ambiguity at different linguistic levels (as defined by Chomsky, 1965) differentially affect the time required to complete ambiguous sentences?

An earlier study indicated that ambiguities at certain linguistic levels were more difficult to discover than at others (MacKay \& Bever, forthcoming). The levels were the underlying structure level, the surface or derived structure level, and the lexical or word level. Since the nature and types of ambiguity are discussed in detail in the earlier paper, examples of the three types of ambiguity are all that are necessary here. Lexical ambiguity involves a change in the dictionary meaning of a word or phrase, such as The rest of the army was insufficient. Derived-structure ambiguity involves a change in the manner in which words are grouped into phrases, such as They sent the requisition over a week

1 This work was supported by a contract with the Department of of Dejense ARPA 187; NASA grant Ns6496; and an MIT intramural fellowship. The author wishes to thank Dr. H.-L. Teuber, Dr. N. Chomsky and Dr. W. Wickelgren for their excellent sugoestions; Dr. T. G. Bever for examining the ambiguities; and the Harvard Center for Cognitive Studies for providing subjects. ago. Underlying structure ambiguity involves only a change in the essential relations between words, such as The growing of the flowers was marvelous.

In the previous study, we found that the meanings of an ambiguous sentence could be discovered most easily in the case of lexical ambiguity, followed by derived-structure ambiguity (harder), and underlyingstructure ambiguity (hardest). The interpretation suggested then was that these relative perception times reflected the order in which linguistic levels are processed. If the lexical level of sentences is processed first, lexical ambiguities would be easiest to discover; if the derived structure is processed next, derived-structure ambiguities would take longer to find; and if the underlying structure is processed last, underlying structure ambiguities would be discovered last, as was found. However, although processing of sentential material could have occurred in the search for ambiguity on a single linguistic level, this would not be possible in completing ambiguous sentences. All three linguistic levels must be tackled before a relevant completion can be made. Consequently, there should be no difference in the time required to complete sentence fragments containing these three types of ambiguity in the present study, unless additional factors are involved.

The main purpose of the present paper was to gain some insight into the manner in which ambiguous sentences are normally understood. There are at least three ways in which ambiguity in language could be handled:

\section{The Suppression Hypothesis}

The concept of suppression has been postulated to describe the apparent dominance of one eye over the other in retinal-rivalry. Suppression also proved useful as a concept in studies of ambiguous figures where one figure is seen (e.g., the mother-in-law) but not the other (the wife) (Boring, 1942). A similar phenomenon in the comprehension of language would be the perceptual domination of one of the meanings of ambiguous sentences over the other. For example, the suppression hypothesis would suggest that for the ambiguous sentence Eichmann was lying when the lawyer entered one could perceive Eichmann lying either on his back or through his teeth, but not neither and not both simultaneously. To extend this hypothesis, let us assume that underlyingstructure ambiguities were most difficult to discover in the 1965 study because the second meaning of underlyingstructure ambiguities was suppressed to a greater extent than the second meanings for derived andlexical ambiguities. If ambiguity interferes with the processing of sentences, then less suppression of the second 


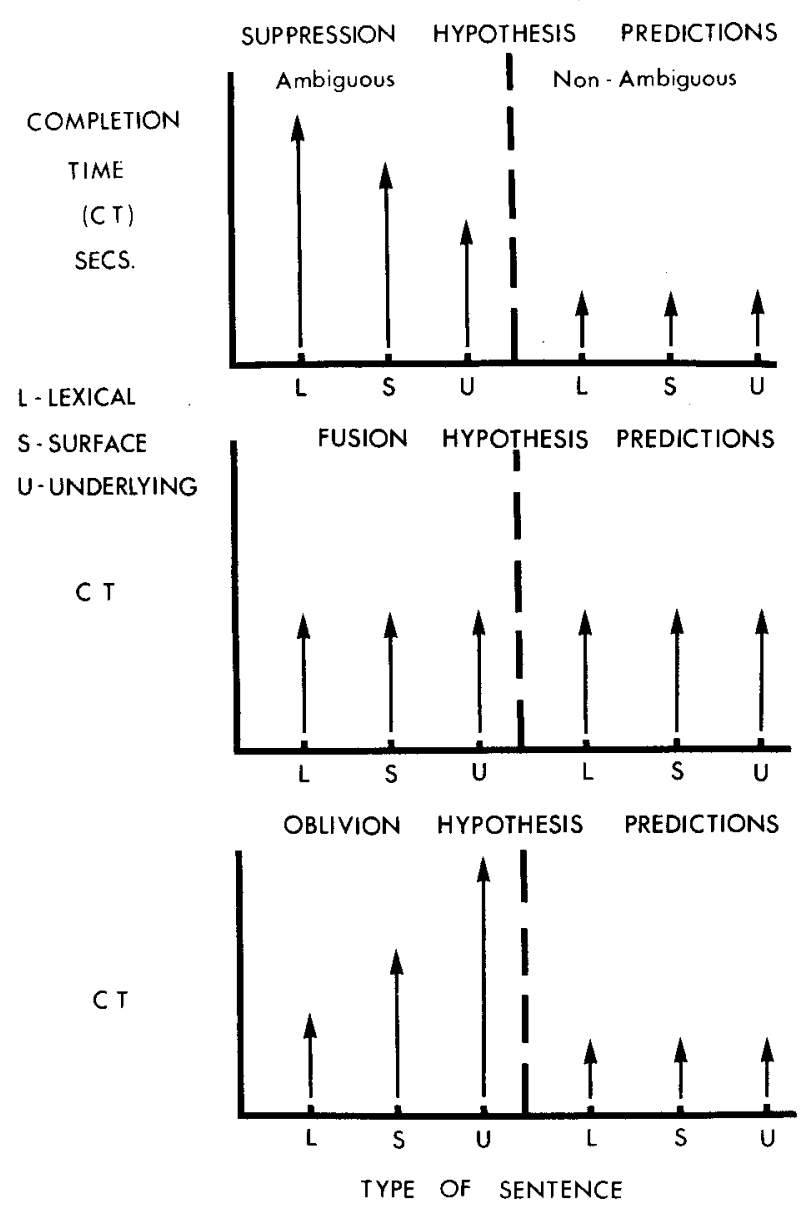

Fig. 1. Predictions for the completion times for the three types of ambiguous sentence fragments, based on three hypotheses of the processing of ambiguity discussed in the text.

meaning of lexically ambiguous sentences should mean that these sentences should take longer to complete than those with ambiguity at the derived and underlying structure levels. Further, since suppression presumably takes time as well as effort, ambiguous sentences should always take longer to complete than unambiguous ones. These predictions are shown in Fig. 1a.

\section{The Fusion Hypothesis}

For slightly disparate retinal images, fusion is the rule rather than the exception. An analogous phenomenon in the comprehension of language would be the simultaneous perception of both meanings of ambiguous sentences with both meanings contributing to a single integrated interpretation. For example, both meanings of the phrase the three masted ships could be combined in the interpretation three ships with three masts. The result. of the 1965 study may have reflected differences in the relative ease of separating two perceptually fused meanings at the lexical level as compared to perceptually fused meanings at the surface and underlying structure levels. In fact, one subject claimed to have difficulty finding the second meaning for one sentence (viz., "The soldier put gasoline into the tank") because his interpretation involved "a soldier putting gasoline into the tank of a tank. "However, in completing ambiguous sentences the separation of perceptually fused meanings would be unnecessary. Consequently, the fusion hypothesis predicts no differences in the completion times among the three types of ambiguity, and between ambiguous and non-ambiguous sentences, as shown in Fig. $1 b$.

\section{The Oblivion Hypothesis}

A third possibility is that neither meaning of an ambiguous word or set of words may be seen until the ambiguity is resolved on the basis of the non-ambiguous context of the sentence. In the earlier study, subjects reported seeing neither meaning for certain ambiguous sentences. In these cases, differences in perception time may have reflected differences in the ease of attaining the first meaning (i.e., it may have been easier to understand one meaning in the case of lexical than in the case of derived and underlying structure ambiguities). The discovery of the second meaning in that study may have been a separate and extraneous process requiring about the same amount of time for all types of ambiguity. Assuming that a single meaning is both necessary and sufficient for the relevant completion of sentences, these predictions follow from the Oblivion Hypothesis: first, assuming that no meaning is seen for some period-however brief-in the case of ambiguous sentences, these should take longer to complete than unambiguous sentences. And second, if a single meaning can be attained most readily for lexical ambiguities, they should be completed sooner than derived and underlying structure ambiguities, as shown in Fig. 1c.

As in the earlier study, multiply ambiguous sentences (containing two ambiguities or four distinct meanings) were included in the present study. Discovery of two meanings in multiply ambiguous sentences took longer than discovery of two meanings in singly ambiguous sentences in the 1965 study. Two hypotheses which could explain that result give divergent predictions for the present study. One hypothesis is that extra time was needed to decide which ambiguity to report for multiply ambiguous sentences. Since the choice between ambiguities is not necessary for the completion of multiply ambiguous sentences, no difference in completion times for singly and multiply ambiguous sentences would be expected in the present study under that hypothesis.

\section{Procedure}

\section{METHOD}

Two groups of twenty undergraduates were paid for their participation in the hour-long experiment. The subject's task was to flip over a $3 \times 5$ in. index card, on which the sentence fragments were typed, think up 
a relevant completion for the fragment, and then say the entire sentence out loud. Completions were to be concise, grammatical, and, most important, relevant to the meaning of the sentence fragment. The subject was warned that he might have to defend relevance of any completion that $\mathrm{E}$ challenged. $\mathrm{E}$ presented each card face down, started a stop watch as soon as the subject flipped over the card, and stopped it as soon as he completed the sentence. $E$ was unaware of the nature of the ambiguity prior to any trial. Where the subject's completion did not seem to have any connection to the meaning of the words on the card, E asked the subject what the connection was. Only if the subjectagreed that his completion had no immediate relevance to the sentence, was the completion scored as "tangential." $\mathrm{E}$ then recorded the trial number, the completion time, the completion and the number of words. Each trial required about $45 \mathrm{sec}$. The cards were thoroughly shuffled for each subject in order to eliminate any systematic interaction between one sentence and the following ones. When the completion time for an ambiguous sentence was abnormally long, E asked why it took so long. At the end of the experiment $E$ told the subject that two thirds of the sentences were ambiguous and asked if he had noticed an ambiguity while reading any of the sentences. If a subject replied that he had noticed two meanings for any of the sentences, his data were analyzed separately from the others. E then asked the subjects which of the two meanings he saw for ambiguous sentences where his completion did not make this clear. Materials

Two hundred and ten sentences were used in this experiment. Half of them are shown in Appendix A. Forty-two of the sentences were singly ambiguous, 14 from each of the three types of ambiguity, and for each of these there was a non-ambiguous version, making 84 ; 21 were multiply ambiguous, making 105 , as shown in Appendix $A$.

Most of the ambiguities were taken from the "nonbiased range" in the original study (i.e., those sentences in the 1965 study for which the two meanings were found to be about equally likely, in terms of the relative number of subjects seeing one of the meanings first).

The non-ambiguous versions were constructed making the smallest change possible in the ambiguous sentence to approximate one of the two meanings selected at random. For example, Although he mentioned the problems with the bishop became Although he mentioned the problems to the bishop in the non-ambiguous version, and Although he was continually bothered by the cold became Although he was continually bothered by the headache in non-ambiguous form. Ten randomly chosen subjects from the first group received seven of the ambiguous sentences and the non-ambiguous version of the remaining seven ambiguous sentences. The other half of the first group of subjects received the remaining sentences. All subjects in both groups received the 21 incomplete sentences with two separate ambiguities.
Exactly the same experimental design was used with the other group of 20 subjects, except that different sentences were employed. These sentences contained the same ambiguities and number of words as the sentences shown in Appendix A, except that the 42 singly ambiguous sentences contained the 42 ambiguities from the multiply ambiguous sentences of the first group, and the 21 multiply ambiguous sentences contained the 42 ambiguities from the singly ambiguous sentences shown in Appendix A. This meant that the singly ambiguous and unambiguous sentences in one group served as control sentences for the multiply ambiguous sentences in the other.

The incomplete sentences were of three types: those without either subject or verb (labeled 1 in Appendix A); those without a verb (labeled 2); and those with subject and verb but no object (labeled 3). There was an equal number of each sentence type for lexical, derived and underlying-structure ambiguities. The purpose of this arrangement was to ensure that completions did not fall into a stereotyped grammatical structure. For similar reasons, the subject of half of the sentences was a personal pronoun, such as I or we, and for the other half, the name of a famous person, such as Kennedy or Roosevelt.

\section{RESULTS}

At the end of the experiment only three subjects reported noticing that any of the sentences was ambiguous during a trial, although six subjects reported seeing a second meaning after they completed a sentence. Only the first three subjects were omitted from the sample, and extra subjects were run to fill their places in the experimental design. Later analysis showed that their results were similar in all respects to those of the 40 who seemed to ignore the ambiguity. Several subjects reported that some of the sentences were confusing or made no sense at first, although they did not report any of the ambiguities.

The results can be divided into two parts: (A) Completion time resuits: An analysis of the completion times for the various types of sentences; and (B) Nature of the completions: Examples of the nature of the completions and an analysis of the frequency of misreadings, ungrammatical and tangential completions.

\section{(A) Completion Times}

The relative ordering of completion times was identical for both groups of subjects. Unambiguous sentences for both groups of subjects were completed fastest (with no systematic differences among the three types of unambiguous fragments); lexically ambiguous fragments were completed next; fragments with ambiguity in their derived structure more slowly; and fragments with ambiguity in their underlying structure, even more slowly. Multiply ambiguous sentences took longest to complete for both groups of subjects. For multiply ambiguous sentences, the median completion time was $10.2 \mathrm{sec}$., which is sig- 


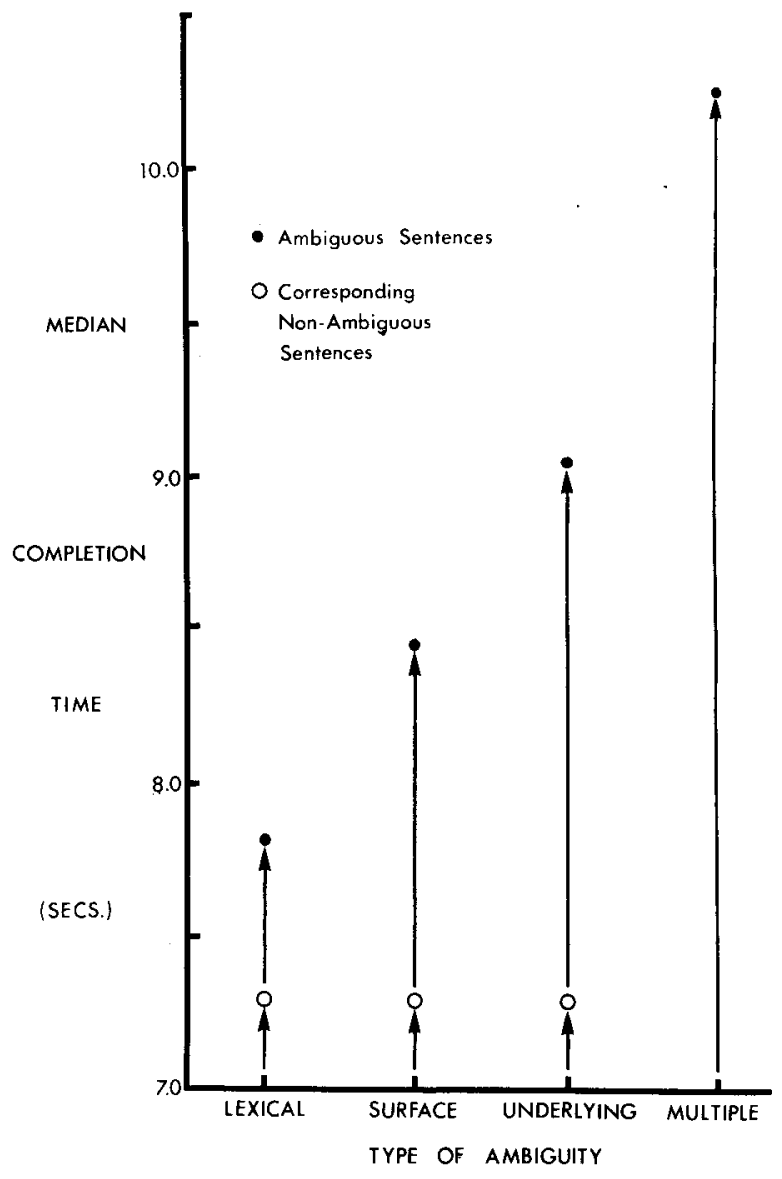

Fig. 2. The median completion time for multiply ambiguous sentence fragments for the three types of ambiguous sentence fragments and for their corresponding non-ambiguous fragments.

nificantly longer than for singly ambiguous sentences at the .01 level, using a Mann-Whitney U-Test.

The median completion time for single lexical ambiguities (for both groups) was 7.73 sec. and for their corresponding non-ambiguous sentences, 7.23 sec.; for surface-structure ambiguities, 8.71 sec., and 7.51 sec. for their corresponding unambiguous sentences; for underlying ambiguities, $9.05 \mathrm{sec}$. and 7.29 sec. for their corresponding unambiguous sentences.

The differences between lexical and surface, and between surface and underlying structure ambiguities were significant at the .01 level using a Mann-Whitney U-Test. The completion time for ambiguous sentences was also significantly longer than for unambiguous sentences using the same test. There was no significant difference between the three types of non-ambiguous sentences.

We formulated the following method to factor out differences in the structural complexity of the various. types of sentences: assuming that differences in the structural complexity of ambiguous sentences will be reflected in the completion times of the unambiguous sentences derived from them, we need only devise . a ratio which will adjust the completion times for the three types of unambiguous sentences to the same value. Multiplying the completion times of the corresponding types of ambiguous sentences by this ratio would then correct for differences in structural complexity.

We chose to adjust the completion times of unambiguous sentences to $7.29 \mathrm{sec}$, so that our correction ratios were $\frac{7.29}{7.23}$ for lexical ambiguities, $\frac{7.29}{7.29}$ (i.e., 1.0) for surface structure ambiguities, and $\frac{7.29}{8.71}$ for underlying structure ambiguities. Multiplying the completion times by this correction ratio, we obtain the adjusted values shown in Fig. 2. Here it can be seen that the differences between the three types of ambiguity are maintained even with corrections for structural complexity.

Completion times for the various types of multiply ambiguous sentences are shown in Fig. 3. Examination of Fig. 3a indicates that sentence fragments with two lexical ambiguities were easier to complete than those with two surface or two underlying-structure ambiguities. These differences are significant at the .01 level, as shown by a Mann-Whitney U-Test. However, sentences with ambiguities on the same level were easier to complete than sentences with ambiguities at two different levels, as shown in Fig. 3b (significant at the .01 level with a Mann-Whitney U-Test). The relative completion times for these latter sentences also fell into a pattern consistent with the results for single ambiguities: sentences containing both lexical and surface structure ambiguities were easier to complete than those containing both lexical and underlying ambiguities, and hardest to complete were those containing both underlying and surface ambiguities.

There was a low but significant correlation between the number of words in the completions and completion times for the various types of sentences $\left(r_{\mathrm{s}}=.60\right.$, significant at the .05 level). However, there were no significant differences in the number of words used to complete ambiguous as compared to unambiguous sentences ( $\alpha=.05$, two-tailed sign test). Further, none of the other results discussed above could be attributed to differences in the number of words in the subject's completions as indicated by the median number of words for the various types of ambiguity shown in Table 1 .

Finally, there was no difference between the completion times of the three types of sentences (i.e., without subject, (1); without verb, (2); and without object, (3); (Mann-Whitney U-Test)), a finding which cannot be readily interpreted, but which corroborates a similar finding reported by Forster (in preparation). However, sentences with famous person subjects required significantly more time to complete than those with personal pronoun subjects, a result which may reflect a difference in the availability of factual as compared to personal knowledge. 


\begin{tabular}{|c|c|c|c|c|c|}
\hline $\begin{array}{l}\text { Type of } \\
\text { Ambiguity }\end{array}$ & $\begin{array}{l}\text { Misreadings of } \\
\text { Sentence Fragment }\end{array}$ & $\begin{array}{l}\text { Ungrammatical } \\
\text { Completion }\end{array}$ & $\begin{array}{l}\text { Tangential } \\
\text { Completion }\end{array}$ & Stuttering & $\begin{array}{l}\text { Median Number } \\
\text { of Words }\end{array}$ \\
\hline $\begin{array}{l}\text { Lexical } \\
(n=28)\end{array}$ & 8 & 26 & 9 & 15 & 5.13 \\
\hline $\begin{array}{l}\text { Normal } \\
(n=28)\end{array}$ & 2 & 13 & 5 & 6 & 4.25 \\
\hline $\begin{array}{l}\text { Surface } \\
(n=28)\end{array}$ & 15 & 21 & 14 & 15 & 4.87 \\
\hline $\begin{array}{l}\text { Normal } \\
(n=28)\end{array}$ & 4 & 12 & 5 & 4 & 4.38 \\
\hline $\begin{array}{l}\text { Underlying } \\
(n=28)\end{array}$ & 6 & 34 & 21 & 15 & 4.88 \\
\hline Normal & 6 & 14 & 8 & 5 & 4.5 \\
\hline
\end{tabular}

$(n=28)$

\section{(B) Nature of the completions}

Seven somewhat qualitative aspects of the completions showed marked differences between ambiguous and non-ambiguous sentences. More ambiguous than unambiguous sentences were misread or evoked ungrammatical, irrelevant or tangential completions (as shown in Table 1). However, the nature of the completions was disregarded in the calculation of completion times in the previous section.

1. Misreadings. Misreadings could be classified into four main categories corresponding to the four most frequent types of spelling and word transformation errors in experiments in short-term memory (MacKay, 1966). These are deletion (most frequent), substitution,

addition, and inversion (least frequent). An example of deletion was the misreading of When Kennedy entered the office of the president as When Kennedy entered the office of President. An example of substitution was the misreading of After stopping arguing in the street, Wimbleton (a multiple ambiguity) for After stopping arguing in the court. An example of both substitution and addition can be found in the misreading of Although the idea of Hitler was awful as Although that idea of Hitler's was awful. A further example of addition and substitution is the misreading of Sending it over a week ago to the man with Jack (a multiple ambiguity) as Sending it over a week ago to the man with the jack. An example of addition alone is the mis-

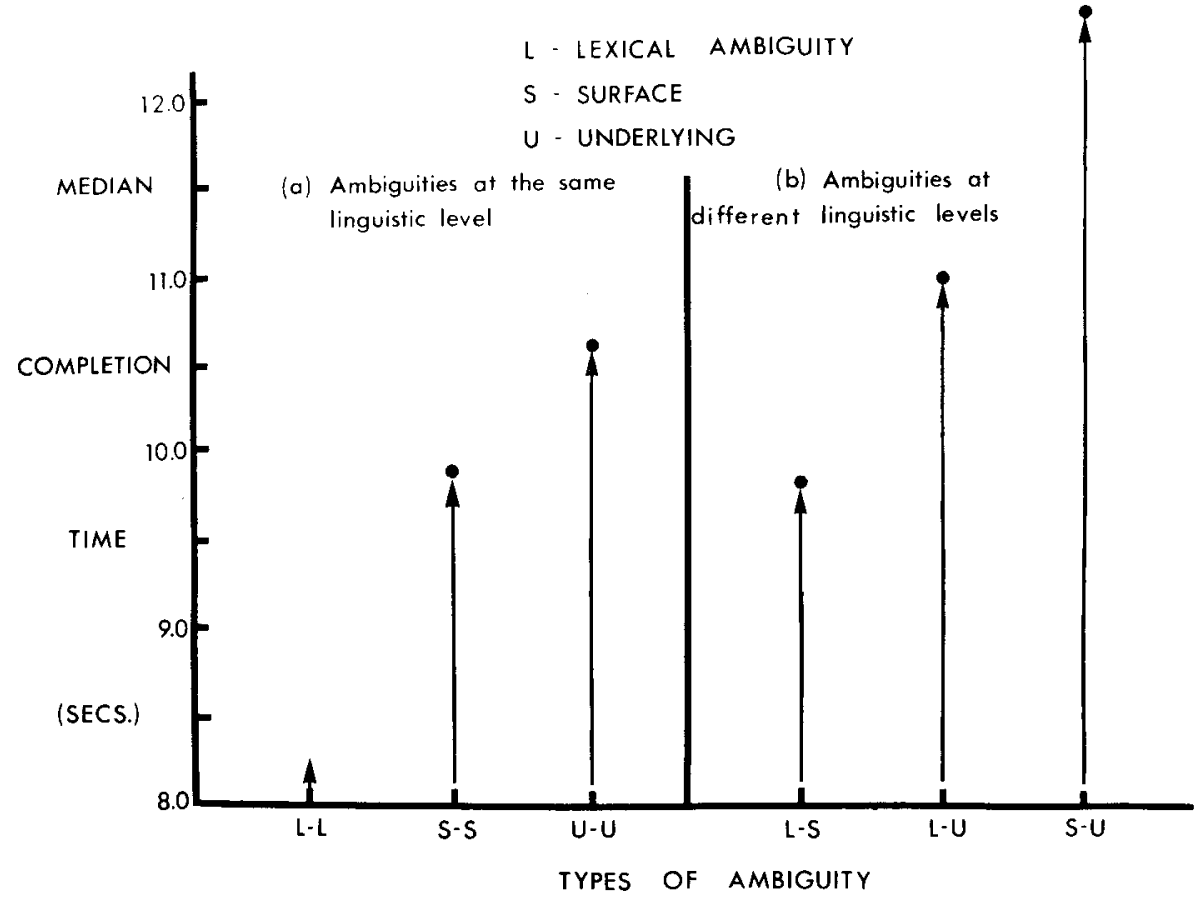

Fig. 3. The median completion time for the six types of multiply ambiguous sentence fragments, with ambiguities at (a) the same linguistic level, and at (b) different linguistic levels. 
reading of Since he didn't like annoying salesmen as Since he didn't like the annoying salesmen. Examples of addition and inversion are found in the misreading of Knowing John was eager to help with her cooking as Knowing John was eager to help her with the cooking.

In all cases the subject made the error in reading what was on the card, and neither corrected the error nor noticed it until the experimenter pointed it out later. There were 43 misreadings, and 28 of these involved ambiguous sentences. The difference between the frequency of misreadings for ambiguous and nonambiguous sentences was significant at the .01 level (Chi-square). The fact that many of the misreadings of ambiguous sentences tended to eliminate the ambiguity as in the above examples is of obvious interest.

2. Tangential completions. The instructions emphasized that completions had to be relevant to the meaning of the words in the sentence fragment. The subjects agreed on 61 trials that their completion was tangential. There were more tangential responses for ambiguous (44) than for unambiguous sentences (17), a difference significant at the .01 level (Chi-square test). Also there were more tangential completions for derived (14) than lexical (9) ambiguities, and for underlying (21) than derived (14). Examples of tangential completions for the following sentence fragment, Claiming the shouting of the Indians was dreadful, Champlain (unambiguous) were: "went on an expedition"'; "ordered his men to fire"'; "starteda war." "Examples of relevant completions for the same fragment were: "covered his ears"'; "gagged them"; "made them be quiet."

An interesting finding, where the subject of the incomplete ambiguous sentence was a personal pronoun, was a high frequency of tangential completions similar to the following: Although I asked how old George was, I mumbled; Knowing that visiting relatives could be bothersome, I was confused; In ordering the police to stop drinking he became very undecided.

An observation congruent with such tangential completions was the frequent occurrence of stuttering and word indecision for ambiguous sentences.

3. Word indecision. Examples of word indecision are: "Having a ball with his case, Merry Pason, I mean Perry Mason ...." and "Before stopping arguing in the court, Wimbleton was perjured, I mean disqualified." There were 22 instances of word indecision, 16 for ambiguous sentences and 7 for unambiguous ones, a difference significant at the .05 level (Chi-square).

4. Stuttering. Noticeable stuttering occurred on 66 trials. Of these, 45 instances of stuttering occurred with ambiguous sentence fragments as compared to 21 for unambiguous ones, a difference significant at the .001 level (Chi-square).

5. Laughter. One female subject expressed inexplicable amusement in the form of just audible chuckling on 22 of the 63 trials. When later questioned, the subject was unaware of laughing or that any of the sentences was amusing. Twenty instances of laughter occurred during ambiguous sentence fragments and only two during unambiguous ones, a difference significant at the .05 level (two-tailed binomial test).

6. Effects of the unseen meaning. Even though the subjects could confidently specify which of the two meanings he was conscious of, the other "unseen" meaning was frequently expressed in their completion of the sentence. For example, consider the following sentence completions: Sailing the two masted ships into the dock, Drake accidentally rammed the pilings, and, for the same fragment, Drake suddenly lost control of the ship. Claiming the work was done over on the roof, (fragment) we had them do it over, (completion) and, he asked them to do it again (completion). Discussing the problems with the mathematicians in Germany, Oppenheimer (fragment) disagreed (completion); grew red in the face (completion); and violently disagreed with their views. Because Stalin liked the old school, he (fragment) decided to exterminate the new one. The subject volunteered that this sentence was ungrammatical, since the verb exterminate could not apply to schoolhouses. He was unaware of seeing the other meaning of "school."

7. Ingrammatical completions. Sixty-six of the 2520 completions were recognized by the subjects to be ungrammatical. Of these, 52 were completions of ambiguous sentences and 14 of unambiguous ones (a difference significant at the .001 level, Chi-square test). Examples of ungrammatical sentences are: "When Freud fed her dog biscuits, he thought he saw them secrete saliva"; "Knowing the minister's hope of marrying Anna was impractical, he disbanded the idea"'; "Knowing the children had a ball at the beach, he asked if he could do it again." These examples suggest that some ungrammatical completions of ambiguous sentences may reflect the dual influence of two incompatible meanings on the subject's completions. One subject even explained one of his ungrammatical completions as the product of confusion (without specific awareness of the ambiguity, however).

\section{DISCUSSION}

First let us consider the three main hypotheses concerning the understanding of ambiguous sentences outlined in the introduction:

\section{The Suppression Hypothesis}

The precise form of the suppression hypothesis given in the introduction clearly does not fit the present data. If the results of $\underline{I n}$ search of ambiguity (MacKay, 1965) were to be entirely explained in terms of suppression, the second meaning of lexical ambiguities must be less effectively suppressed than that of surface and underlying structure ambiguities. Since ambiguity interfered with sentence completion in the present study, we could reasonably assume that sentences whose second meaning is less suppressed, or more prevalent, would be more difficult to complete. Consequently, lexically ambiguous sentences should have been more difficult to complete than sentences with ambiguity at the surface 
and underlying levels. Since the opposite result was obtained, suppression cannot be considered the sole determinant of the differences among the three types of ambiguity in either experiment.

Suppression may still be required to explain the fact that subjects saw only one meaning in processing ambiguous sentences. In contrast to the striking effects of ambiguity on completion time, nature of completions, reading, fluency, and laughter, the absence of awareness of both meanings for ambiguous sentences is indeed remarkable. That only one meaning was seen by most subjects is corroborated by the nature and number of misreadings of ambiguous sentences, and the ease with which subjects could recall which meaning they had seen when later questioned.

However, such effects of linguistic alternatives, without full awareness of all aspects of those alternatives, need not mean that the second meaning is suppressed or that perception of the first meaning is contingent upon the active suppression of the second meaning. The actual process of understanding ambiguous sentences may be a rapid and unanalyzed decision of the sort which must frequently occur in processing natural language. Whether the lack of awareness is due to the rate or the nature of the decision cannot yet be determined.

\section{The Fusion Hypothesis}

The present data also show that fusion cannot be the sole determinant of the time needed to discover ambiguities and to complete ambiguous sentences. If the two meanings of an ambiguous sentence are seen as fused, with the same ease as a single meaning in unambiguous sentences, then there should have been no difference in the completion times for different types of ambiguity and between ambiguous and nonambiguous sentences. The fact that both types of differences occurred tends to contradict the fusion hypothesis. The ease with which subjects could determine which meaning they saw, the nature of the misreadings, ungrammatical and tangential completions, and the stuttering and word indecision for ambiguous sentences are also at variance with this hypothesis. Again, however, this does not mean that fusion was not occurring for some of the sentences or to some extent for all of the sentences, or that fusion of the two meanings of ambiguous sentences might not have been demonstrated by some other experimental technique.

\section{The Oblivion Hypothesis.}

Under the oblivion hypothesis the difficulty in discovering ambiguities lies in the understanding of a single meaning for ambiguous sentences. There are five sources of support for the oblivion hypothesis: First, the oblivion hypothesis predicted that ambiguous sentences would take more time to complete than unambiguous ones, as was found. Second, the subjects' reports (both during and after the experiment) that ambiguous sentences were difficult to understand, directly support an oblivion hypothesis. Third, the completion-time data supported the specific form of the oblivion hypothesis outlined in the introduction. In order to integrate the oblivion hypothesis with the results of the 1965 study we assumed that discovery of the first meaning in the search for ambiguity was easier for lexical than for surface and underlying ambiguities. Assuming that a single meaning is sufficient and necessary to complete sentences, the oblivion hypothesis predicted greater difficulty in the relevant completion of surface and underlying ambiguities than lexical ambiguities, as was found. Fourth, the oblivion hypothesis predicted that discovery of a single meaning for multiply ambiguous sentences would take longer than for singly ambiguous ones, implying both more time to discover the two meanings for multiple ambiguities, and more time to complete them, as was found. Finally, the oblivion hypothesis accurately predicted the relative order of difficulty in completion of the six types of multiply ambiguous sentences.

Assuming the correctness of the oblivion hypothesis, the fact that sentences with ambiguity at two different linguistic levels took longer to complete than those with two ambiguities on the same level can be seen to support the theory that psychological understanding of a sentence requires the combined appreciation of all three of its linguistic levels. If the processing and completion of sentences did not require the combined understanding of all three levels, then ambiguities at different levels should have had no more effect than the same number of ambiguities at a single level. On the other hand, if completion of sentences requires the understanding of all three levels in conjunction, and no meaning can be gained from a single linguistic level, a relevant completion may still be possible through the comprehension of the other two levels. However, if no meaning can be gained from either of two levels, then a relevant response would be much more difficult. Consequently, when both ambiguities of a multiply ambiguous sentence occur at the same level, completion time would be shorter than when they occur at different levels, as was found.

\section{The Order-of-Processing Hypothesis}

Linguists have postulated a "logical order" for the processing of sentences, beginning first with an appreciation of the underlying structure, then the surface structure, and finally the lexical level (Chomsky, 1965). Assuming that ambiguities at levels processed first are discovered first, and ambiguities at levels processed later are discovered later, then the results of the 1965 study were the exactopposite of the "logical order" postulated by linguists. However, unlike sentence completion, the task in the earlier study allows for the possibility of artificial search strategies. It is conceivable that the levels could be processed in the "logical order" in discovery of the first meaning, and in the opposite order in discovery of the second one. In any case, we cannot assume that the time to dis- 
cover ambiguity reflects the order in which sentences are normally processed. However, there is every reason to assume that the sentence-completion task represents a close approximation to the natural process of producing and understanding sentences. In contrast to the search for ambiguity where two meanings could be discovered by processing a single linguistic level, all three linguistic levels must doubtlessly be processed before a relevant completion can be made.

Consequently, ambiguity at all levels should have an equal effect regardless of the order of processing of the levels. This means that if the only factor needed to explain differences in the time to discover the various types of ambiguity in the previous study were the order of processing of the levels, there should be no differences in the time required to complete sentence fragments containing these three types of ambiguity in the present study. Since differences occurred, more than the order of processing of linguistic levels must be involved in the search for ambiguity or the completion of ambiguous sentences.

\section{The Structural Complexify Hypothesis}

The inclusion of unambiguous sentences in the present study provided a much needed control for the 1965 study on ambiguity. The reported differences in the time to discover the various types of ambiguity could have reflected differences in the structural complexity of the sentences. If lexically ambiguous sentences were least complex, sentences containing surface-structure ambiguities more complex, and sentences containing underlying-structure ambiguities most complex, structural complexity could explain the obtained results independently of the level at which the ambiguity occurred. However, in the present study, differences in the time to complete ambiguous sentences due to structural complexity would cause corresponding differences in completion time for unambiguous sentences derived from them. Assuming lexically ambiguous sentences to be least complex, the time to complete the unambiguous sentences derived from them should be shortest, and assuming sentences with underlying structure ambiguities to be most complex, the unambiguous sentences derived from them should have taken longest to complete. That they did not tends to suggest that structural complexity was the prime determinant of neither the time to discover ambiguity nor the time to complete ambiguous sentences.

The frequency and nature of the ungrammatical completions suggested that some subjects responded before deciding on a single meaning for ambiguous sentences, the result being an incompatible compromise between the two meanings. The tendency for the "unseen" meaning to enter into completions suggested a similar sort of cognitive compromise rather than a simple decision favoring one of the two meanings for some of the ambiguous sentences.

The relative frequency of tangential completions (most tangential completions for underlying structure ambiguities, and least for lexical ambiguities) is open to several interpretations. Probably the simplest is that tangential completions reflect a tendency to respond before fully understanding a sentence. Under the oblivion hypothesis, understanding of a single meaning is easier for lexical than for derived and underlying ambiguities. Consequently, the probability of responding before fully understanding underlying ambiguities would be greater than for surface and lexical ambiguities, as was found.

The frequency of word indecision and stuttering suggested that the dual interpretations of ambiguities may generate conflict which some psychologists consider to be causally related to hesitant and non-fluent utterance (Johnson, 1959). However, the exact nature of this conflict could not be conclusively determined from the nature of the stuttering, and word indecision, and their frequency was quite independent of the type of ambiguity.

The predominant occurrence of tittering for ambiguous sentences is of considerable theoretical interest, even though it was recorded for only one subject. The theory of laughter to be advocated here is a modification of a theory proposed by Spencer and others (Piddington, 1963). It views laughter as a displacement activity, similar to that discussed by ethologists (Tinbergen, 1951) and occurring only if two incompatible tendencies or drives are strongly and simultaneously aroused. That the two incompatible meanings of ambiguous sentences should provoke the displacement activity, laughter, for all subjects is not to be expected, since the criterion "strongly aroused" is probably infrequently met with ambiguous sentences.

Finally, the present results suggest several practical applications, one of which concerns the use of sentence completion and word association as a projective technique. Clinical psychologists have been interested in the time to complete sentences as an indicator of "mental blocking" or emotional involvement (Holsopple \& Miale, 1954). Since we have found that ambiguity will influence the time to complete sentences, ambiguous sentences in projective tests may have inordinate completion times for reasons quite independent of emotional involvement or mental blocking. Consequently care should be taken in the construction of sentences for projective tests to ensure that they a re unambiguous or contain the same number and types of ambiguity.

\section{SIIMMARY}

A study of the time required for subjects to complete ambiguous sentences supports the following conclusions:

1. Even though none of the subjects reported being aware of the ambiguities while completing the sentences, they took longer to complete ambiguous sentences than unambiguous ones.

2. The completion time for sentences with more than one ambiguity was significantly longer than completion time for sentences with only one ambiguity.

3. Completion time is less for lexical than for surface and underlying structure ambiguities.

4. The relative completion times for the three types 
of ambiguity in sentences containing more than one ambiguity was identical to that found for completion of singly ambiguous sentences.

5 . Sentences with two ambiguities occurring at different linguistic levels took more time to complete than sentences with both ambiguities on the same linguistic level.

Several theories of the nature of processing of ambiguity in sentences were discussed. The present results suggested that ambiguity interferes with the appreciation of a single meaning of ambiguous sentences and that this difficulty is progressively greater for lexical, derived, underlying, and multiple ambiguities in that order.

\section{References}

Boring, E. G. Sensation and perception in the history of experimental psychology. New York: Appleton Century Crofts, 1942.

Chomsky, N. Aspects of the theory of syntax. Cambridge: The Massachusetts Institute of Technology Press, 1965.

Forster, K. N. Linguistic structure and sentence production. In The structure and psychology of language. New York: Holt, Rinehart and Winston (in preparation).

Holsopple, J. Q., \& Miale, F. R. Sentence completion - a projective method for the study of personality. Springfield: Thomas Press, 1954.

Johnson, $W$. et al. The on set of stuttering. Minneapolis: University of Minnesota Press, 1959.

Mackay, D. G. Temporal disintegration of behavior, in press, 1966.

MacKay, D. G., \& Bever, T. G. In search of ambiguity. Forthcoming.

Piddington, R. The psychology of laughter. New York: Gamut Press, 1963.

Tinbergen, R. The study of instinct. Oxford: Oxford University Press, 1951 .

\section{(Accepted for publication October 31, 1966.)}

Appendix A: The 105 incomplete sentences for the first group with the type of ambiguity, type of sentence and completion times as indicated.

(Where (1) represents sentences without a subject; (2), without a verb; and (3), without an object.)

\begin{tabular}{|c|c|c|}
\hline & $\begin{array}{c}\text { Type of } \\
\text { Ambiguity } \\
\text { (sentence type) }\end{array}$ & $\begin{array}{c}\text { Median } \\
\text { Completion } \\
\text { Time }\end{array}$ \\
\hline $\begin{array}{l}\text { 1. After taking the right turn at the } \\
\text { intersection, I }\end{array}$ & $\begin{array}{l}\text { Lexical } \\
\text { (2) }\end{array}$ & 6.1 \\
\hline $\begin{array}{l}\text { 2. After taking the left turn at the } \\
\text { intersection, I }\end{array}$ & $\begin{array}{l}\text { Normal } \\
\text { (2) }\end{array}$ & 5.0 \\
\hline $\begin{array}{l}\text { 3. Although I knew the new position } \\
\text { had advantages, }\end{array}$ & $\begin{array}{l}\text { Lexical } \\
\text { (1) }\end{array}$ & 5.9 \\
\hline $\begin{array}{l}\text { 4. Although I knew my new job had } \\
\text { advantages, }\end{array}$ & Normal & 6.0 \\
\hline $\begin{array}{l}\text { 5. Even though everyone knew } \\
\text { Capone was making money, }\end{array}$ & $\begin{array}{l}\text { Lexical } \\
\text { (1) }\end{array}$ & 6.4 \\
\hline $\begin{array}{l}\text { 6. Even though everyone knew } \\
\text { Capone was becoming rich, }\end{array}$ & $\begin{array}{l}\text { Normal } \\
\text { (1) }\end{array}$ & 7.2 \\
\hline $\begin{array}{l}\text { 7. After her injury that summer } \\
\text { she couldn't bear }\end{array}$ & $\begin{array}{l}\text { Lexical } \\
(3)\end{array}$ & 6.7 \\
\hline $\begin{array}{l}\text { 8. After her injury that summer, } \\
\text { she couldn't lift }\end{array}$ & $\begin{array}{l}\text { Normal } \\
(3)\end{array}$ & 5.4 \\
\hline
\end{tabular}

9. Although Nixon was still standing by the platform

10. Although Nixon was still standing by the rostrum

11. When Kennedy entered the office of the president

12. When Kennedy entered the garden of the president

13. Although I was continually bothered by the cold,

14. Although I was continually bothered by the climate,

15. Eichmann, who was lying when the lawyer entered,

16. Eichmann, who was talking when the lawyer entered,

17. Out of sympathy for the poor people, Rockefeller

18. Out of sympathy for the working people, Rockefeller

19. Captain Morgan said the port reminded

20. Captain Morgan said the wine reminded

21. Although the solution seemed clear in chemistry class, I

22. Although w.- nnswer seemed easy in chemistry class, 1

23. In suggesting the paper would cover everything, I

24 . In suggesting the book would explain everything, I

25. Before having the tanks filled with gasoline, Rommel

26. Before having the bottles filled with gasoline, Rommel

27. Before I carried out the orders yesterday

28. Before I carried out the garbage yesterday

29. Even if I did laugh at the church, I

30. Even if I did laugh in the church, I

31. When I saw the wild Indian dance, I realized

32. When I saw the wild Indians dancing, I realized

$\begin{array}{cc}\text { Type of } & \text { Median } \\ \text { Ambiguity } & \text { Completion } \\ \text { (sentence type) } & \text { Time } \\ \text { Lexical } & 6.1\end{array}$

(3)

Normal

(3)

Lexical

(1)

Normal

(1)

Lexical

(2)

Normal

(2)

Lexical

(2)

Normal

6.3

(2)

Lexical

(2)

5.6

Normal

(2)

Lexical

(3)

Normal

(3)

Lexical

(2)

Normal

(2)

Lexical

(2)

Normal

(2)

Lexical

(2)

Normal

(2)

Lexical

(3)

Normal

(3)

Surface

(2)

Normal

(2)

Surface

(3)

Normal

(3)
6.8

4.8 


\begin{tabular}{|c|c|c|c|c|c|}
\hline & $\begin{array}{c}\text { Type of } \\
\text { Ambiguity } \\
\text { (sentence type) }\end{array}$ & $\begin{array}{l}\text { Median } \\
\text { Completion } \\
\text { Time }\end{array}$ & & $\begin{array}{c}\text { Type of } \\
\text { Ambiguity } \\
\text { (sentence type) }\end{array}$ & $\begin{array}{l}\text { Median } \\
\text { Completion } \\
\text { Time }\end{array}$ \\
\hline $\begin{array}{l}\text { 33. Although Hannibal sent troops } \\
\text { over a week ago }\end{array}$ & $\begin{array}{l}\text { Surface } \\
\text { (1) }\end{array}$ & 6.3 & $\begin{array}{l}\text { 55. Telling me to go without hesita- } \\
\text { tion, he forgot }\end{array}$ & $\begin{array}{l}\text { Surface } \\
\text { (3) }\end{array}$ & 6.7 \\
\hline $\begin{array}{l}\text { 34. Although Hannibal sent troops } \\
\text { almost a week ago }\end{array}$ & $\begin{array}{l}\text { Normal } \\
\text { (1) }\end{array}$ & 5.2 & $\begin{array}{l}\text { 56. Telling me to go without her, } \\
\text { he forgot }\end{array}$ & Normal & 5.9 \\
\hline $\begin{array}{l}\text { 35. When Huckleberry Finn looked } \\
\text { over the fence, he noticed }\end{array}$ & $\begin{array}{l}\text { Surface } \\
\text { (3) }\end{array}$ & 6.7 & $\begin{array}{l}\text { 57. Although usually quick to } \\
\text { please, he didn't }\end{array}$ & $\begin{array}{l}\text { Underlying } \\
\text { (3) }\end{array}$ & 5.3 \\
\hline $\begin{array}{l}\text { 36. When Huckleberry Finn looked } \\
\text { at the fence, he noticed }\end{array}$ & $\begin{array}{l}\text { Normal } \\
\text { (3) }\end{array}$ & 5.5 & $\begin{array}{l}\text { 58. Although usually eager to } \\
\text { please, he didn't }\end{array}$ & $\begin{array}{l}\text { Normal } \\
\text { (3) }\end{array}$ & 5.4 \\
\hline $\begin{array}{l}\text { 37. Brahms, knowing how great } \\
\text { symphonies sound, played }\end{array}$ & $\begin{array}{l}\text { Surface } \\
\text { (3) }\end{array}$ & 5.5 & $\begin{array}{l}\text { 59. Although the idea of Hitler was } \\
\text { awful, }\end{array}$ & $\begin{array}{l}\text { Underlying } \\
\text { (1) }\end{array}$ & 5.7 \\
\hline $\begin{array}{l}\text { 38. Brahms, knowing that great } \\
\text { symphonies please, played }\end{array}$ & $\begin{array}{l}\text { Normal } \\
\text { (3) }\end{array}$ & 8.0 & $\begin{array}{l}\text { 60. Although that idea of Hitler's } \\
\text { was awful, }\end{array}$ & $\begin{array}{l}\text { Normal } \\
\text { (1) }\end{array}$ & 6,3 \\
\hline $\begin{array}{l}\text { 39. Although I asked how old George } \\
\text { was, I }\end{array}$ & $\begin{array}{l}\text { Surface } \\
(2)\end{array}$ & 5.3 & $\begin{array}{l}\text { 61. Because the suggestion of the } \\
\text { soldiers helped Napoleon, }\end{array}$ & $\begin{array}{l}\text { Underlying } \\
\text { (1) }\end{array}$ & 5.7 \\
\hline $\begin{array}{l}\text { 40. Although I asked about old } \\
\text { George, I }\end{array}$ & $\begin{array}{l}\text { Normal } \\
(2)\end{array}$ & 4.2 & $\begin{array}{l}\text { 62. Because the retreat of the sol- } \\
\text { diers helped Napoleon, }\end{array}$ & $\begin{array}{l}\text { Normal } \\
\text { (I) }\end{array}$ & 7.3 \\
\hline $\begin{array}{l}\text { 41. Although } \frac{\text { Magellan remem- }}{\text { bered how good beef tasted, he }}\end{array}$ & $\begin{array}{l}\text { Surface } \\
\text { (2) }\end{array}$ & 6.9 & $\begin{array}{l}\text { 63. Knowing that visiting relatives } \\
\text { could be bothersome, I }\end{array}$ & $\begin{array}{l}\text { Underlying } \\
\text { (2) }\end{array}$ & 7.4 \\
\hline $\begin{array}{l}\text { 42. Although } \frac{\text { Magellan }}{\text { remem- }} \\
\text { bered how beef steak tasted, he }\end{array}$ & $\begin{array}{l}\text { Normal } \\
\text { (2) }\end{array}$ & 7.7 & $\begin{array}{l}\text { 64. Knowing that some relatives } \\
\text { could be bothersome, I }\end{array}$ & $\begin{array}{l}\text { Normal } \\
(2)\end{array}$ & 5.7 \\
\hline $\begin{array}{l}\text { 43. While I was telling her baby } \\
\text { stories, }\end{array}$ & $\begin{array}{l}\text { Surface } \\
(1)\end{array}$ & 4.7 & $\begin{array}{l}\text { 65. If Captain Cook was the one to } \\
\text { watch, he }\end{array}$ & $\begin{array}{l}\text { Underlying } \\
\text { (2) }\end{array}$ & 6.75 \\
\hline $\begin{array}{l}\text { 44. While I was telling her friend } \\
\text { stories, }\end{array}$ & $\begin{array}{l}\text { Normal } \\
(2)\end{array}$ & 5.1 & $\begin{array}{l}\text { 66. If Captain } \\
\text { complained, he }\end{array}$ & $\begin{array}{l}\text { Normal } \\
\text { (2) }\end{array}$ & 6.9 \\
\hline $\begin{array}{l}\text { 45. When } \text { Freud fed her dog bis- } \\
\text { cuits, he thought }\end{array}$ & $\begin{array}{l}\text { Surface } \\
(2)\end{array}$ & 7.7 & 67. Being the one to worship, he & $\begin{array}{l}\text { Underlying } \\
\text { (2) }\end{array}$ & 7.0 \\
\hline $\begin{array}{l}\text { 46. When Freud fed him dog bis- } \\
\text { cuits, he thought }\end{array}$ & $\begin{array}{l}\text { Normal } \\
(2)\end{array}$ & 7.8 & 68. Being the one to pray, he & $\begin{array}{l}\text { Normal } \\
\text { (2) }\end{array}$ & 5.3 \\
\hline $\begin{array}{l}\text { 47. Although they were interesting } \\
\text { and convincing people, nobody }\end{array}$ & $\begin{array}{l}\text { Surface } \\
\text { (2) }\end{array}$ & 5.5 & $\begin{array}{l}\text { 69. Champlain, claiming the shoot- } \\
\text { ing of the Indians was dreadful, }\end{array}$ & $\begin{array}{l}\text { Underlying } \\
\text { (2) }\end{array}$ & 7.7 \\
\hline $\begin{array}{l}\text { 48. Although they were enterpris- } \\
\text { ing and ambitious people, no- } \\
\text { body }\end{array}$ & $\begin{array}{l}\text { Normal } \\
\text { (2) }\end{array}$ & 6.9 & $\begin{array}{l}\text { 70. Champlain, claiming the shout- } \\
\text { ing of the Indians was dreadful, }\end{array}$ & $\begin{array}{l}\text { Normal } \\
\text { (2) }\end{array}$ & 7.2 \\
\hline $\begin{array}{l}\text { 49. Before studying thoroughly } \\
\text { crystalized solutions in chem- }\end{array}$ & $\begin{array}{l}\text { Surface } \\
(2)\end{array}$ & 8.9 & $\begin{array}{l}\text { 71. After saying the growing of the } \\
\text { flowers was marvelous, }\end{array}$ & $\begin{array}{l}\text { Underlying } \\
\text { (1) }\end{array}$ & 7.3 \\
\hline istry, Pasteur & & & $\begin{array}{l}\text { 72. After saying the growth of the } \\
\text { flowers was marvelous, }\end{array}$ & $\begin{array}{l}\text { Normal } \\
\text { (1) }\end{array}$ & 6.15 \\
\hline $\begin{array}{l}\text { 50. Before thoroughly studying } \\
\text { crystalized solutions in chem- } \\
\text { istry, Pasteur }\end{array}$ & $\begin{array}{l}\text { Normal } \\
\text { (2) }\end{array}$ & 8.9 & $\begin{array}{l}\text { 73. Knowing the aircraft to fly long } \\
\text { distances, he }\end{array}$ & $\begin{array}{l}\text { Underlying } \\
\text { (2) }\end{array}$ & 6.0 \\
\hline $\begin{array}{l}\text { 51. Although Bob Hope frequently } \\
\text { delivered delightfully serious } \\
\text { speeches, }\end{array}$ & $\begin{array}{l}\text { Surface } \\
\text { (1) }\end{array}$ & 8.2 & $\begin{array}{l}\text { 74. Knowing the aircraft had flown } \\
\text { long distances, he }\end{array}$ & $\begin{array}{l}\text { Normal } \\
(2)\end{array}$ & 6.3 \\
\hline $\begin{array}{l}\text { 52. Although Bob Hope frequently } \\
\text { delivered quite serious speech- } \\
\text { es, }\end{array}$ & $\begin{array}{l}\text { Normal } \\
(1)\end{array}$ & 7.35 & $\begin{array}{l}\text { 75. Even after several contiguous } \\
\text { performances, Stravinsky still } \\
\text { sounds }\end{array}$ & $\begin{array}{l}\text { Underlying } \\
\text { (3) }\end{array}$ & 8.1 \\
\hline $\begin{array}{l}\text { 53. Although I had worn old tennis } \\
\text { she s, }\end{array}$ & $\begin{array}{l}\text { Surface } \\
\{1\}\end{array}$ & 4.7 & $\begin{array}{l}\text { 76. Even after several contiguous } \\
\text { performances, Stravinsky still } \\
\text { likes }\end{array}$ & $\begin{array}{l}\text { Normal } \\
\text { (3) }\end{array}$ & 7.7 \\
\hline $\begin{array}{l}\text { 54. Although I had worn my tennis } \\
\text { shoes, }\end{array}$ & $\begin{array}{l}\text { Norma1 } \\
\text { (1) }\end{array}$ & 5.5 & $\begin{array}{l}\text { 77. When Eichmann described their } \\
\text { plans for us, we knew }\end{array}$ & $\begin{array}{l}\text { Underlying } \\
\text { (2) }\end{array}$ & 5.95 \\
\hline
\end{tabular}




\begin{tabular}{|c|c|c|c|c|c|}
\hline & $\begin{array}{c}\text { Type of } \\
\text { Ambiguity } \\
\text { (sentence type) }\end{array}$ & $\begin{array}{l}\text { Median } \\
\text { Completion } \\
\text { Time }\end{array}$ & & $\begin{array}{c}\text { Type of } \\
\text { Ambiguity } \\
\text { (sentence type) }\end{array}$ & $\begin{array}{l}\text { Median } \\
\text { Completion } \\
\text { Time }\end{array}$ \\
\hline $\begin{array}{l}\text { 78. When Eichmann described their } \\
\text { plans to us, we knew }\end{array}$ & $\begin{array}{l}\text { Normal } \\
\text { (2) }\end{array}$ & 5.7 & $\begin{array}{l}\text { 93. Since the ones to help were } \\
\text { embarking soldiers, we }\end{array}$ & $\begin{array}{l}\text { Underlying } \\
\text { Underlying } \\
\text { (2) }\end{array}$ & 7.7 \\
\hline $\begin{array}{l}\text { 79. In ordering the police to stop } \\
\text { drinking, he }\end{array}$ & $\begin{array}{l}\text { Underlying } \\
\text { (2) }\end{array}$ & 7.1 & $\begin{array}{l}\text { 94. Claiming the work was done } \\
\text { over on the roof }\end{array}$ & $\begin{array}{l}\text { Lexical } \\
\text { Surface }\end{array}$ & 7.67 \\
\hline $\begin{array}{l}\text { 80. In ordering the police to work } \\
\text { late, he }\end{array}$ & $\begin{array}{l}\text { Normal } \\
\text { (2) }\end{array}$ & 5.7 & & (1) & \\
\hline $\begin{array}{l}\text { 81. When he asked the men to stop } \\
\text { picketing }\end{array}$ & $\begin{array}{l}\text { Underlying } \\
\text { (1) }\end{array}$ & 7.85 & $\begin{array}{l}\text { 95. While lecturing on their stand } \\
\text { in Leningrad, } \underline{\text { Stalin }}\end{array}$ & $\begin{array}{l}\text { Lexical } \\
\text { Surface } \\
(2)\end{array}$ & 8.2 \\
\hline $\begin{array}{l}\text { 82. When he asked the men to go } \\
\text { home }\end{array}$ & $\begin{array}{l}\text { Normal } \\
\text { (1) }\end{array}$ & 4.9 & $\begin{array}{l}\text { 96. Sailing the three masted ships } \\
\text { into the dock, Drake }\end{array}$ & $\begin{array}{l}\text { Surface } \\
\text { Lexical }\end{array}$ & 8.8 \\
\hline $\begin{array}{l}\text { 83. Because I disliked sailing in } \\
\text { the harbor, I asked }\end{array}$ & $\begin{array}{l}\text { Underlying } \\
\text { (3) }\end{array}$ & 5.5 & & (2) & \\
\hline $\begin{array}{l}\text { 84. Because I disliked noise in the } \\
\text { streets, I asked }\end{array}$ & $\begin{array}{l}\text { Normal } \\
\text { (3) }\end{array}$ & 5.7 & $\begin{array}{l}\text { 97. That grade hindering more } \\
\text { rapid progress, I decided }\end{array}$ & $\begin{array}{l}\text { Surface } \\
\text { Lexical } \\
\text { (3) }\end{array}$ & 7.9 \\
\hline $\begin{array}{l}\text { Multiple Ambiguities } \\
\text { 85. Perry Mason, having a ball with } \\
\text { his case, asked }\end{array}$ & $\begin{array}{l}\text { Lexical } \\
\text { Lexical } \\
\text { (3) }\end{array}$ & 6.8 & $\begin{array}{l}\text { 98. Before stopping arguing in the } \\
\text { court, Wimbleton }\end{array}$ & $\begin{array}{l}\text { Underlying } \\
\text { Lexical } \\
(2)\end{array}$ & 8.7 \\
\hline $\begin{array}{l}\text { 86. Noticing the file on the old } \\
\text { school, I }\end{array}$ & $\begin{array}{l}\text { Lexical } \\
\text { Lexical } \\
\text { (2) }\end{array}$ & 6.0 & $\begin{array}{l}\text { 99. After criminal lawyers took the } \\
\text { picture, Fosdick couldn't }\end{array}$ & $\begin{array}{l}\text { Lexical } \\
\text { Underlying } \\
\text { (3) }\end{array}$ & 7.7 \\
\hline $\begin{array}{l}\text { 87. When I took the chair before the } \\
\text { board }\end{array}$ & $\begin{array}{l}\text { Lexical } \\
\text { Lexical } \\
\text { (1) }\end{array}$ & 5.1 & $\begin{array}{l}\text { 100. His visiting physicians provok- } \\
\text { ing a discussion of Adenauer's } \\
\text { age }\end{array}$ & $\begin{array}{l}\text { Lexical } \\
\text { Underlying }\end{array}$ & 9.7 \\
\hline $\begin{array}{l}\text { 88. While I worked on the three } \\
\text { train ferries, }\end{array}$ & $\begin{array}{l}\text { Surface } \\
\text { Surface } \\
\text { (3) }\end{array}$ & 7.5 & $\begin{array}{l}\text { 101. Before taking the plane to } \\
\text { England, Bishop }\end{array}$ & $\begin{array}{l}\text { Underlying } \\
\text { Lexical } \\
(2)\end{array}$ & 6.2 \\
\hline 89. Westmoreland, wondering how & $\begin{array}{l}\text { Surface } \\
\text { Surface } \\
(2)\end{array}$ & 7.2 & $\begin{array}{l}\text { 102. Dissatisfied with the French } \\
\text { interpreter's selection, Ber- } \\
\underline{\text { lioz insisted }}\end{array}$ & $\begin{array}{l}\text { Underlying } \\
\text { Surface } \\
(3)\end{array}$ & 8.3 \\
\hline $\begin{array}{l}\text { 90. Oppenheimer, discussing the } \\
\text { problems with the mathemati- } \\
\text { cians in Germany, }\end{array}$ & $\begin{array}{l}\text { Surface } \\
\text { Surface } \\
\text { (1) }\end{array}$ & 8.6 & $\begin{array}{l}\text { 103. Asking how long flying planes } \\
\text { could be dangerous, I }\end{array}$ & $\begin{array}{l}\text { Underlying } \\
\text { Surface } \\
(2)\end{array}$ & 11.0 \\
\hline $\begin{array}{l}\text { 91. Discussing our fighting as well } \\
\text { as the Germans }\end{array}$ & $\begin{array}{l}\text { Underlying } \\
\text { Underlying } \\
\text { (1) }\end{array}$ & 7.2 & $\begin{array}{l}\text { 104. Approving of her skating at the } \\
\text { pond, I }\end{array}$ & $\begin{array}{l}\text { Surface } \\
\text { Underlying } \\
(2)\end{array}$ & 5.25 \\
\hline $\begin{array}{l}\text { 92. Boone's throwing knives as well } \\
\text { as Bill was }\end{array}$ & $\begin{array}{l}\text { Underlying } \\
\text { Underlying } \\
\text { (3) }\end{array}$ & 8.6 & $\begin{array}{l}\text { 105. After } \frac{\text { James }}{\text { window with the Russian }} \text { broke the } \\
\text { Bund }\end{array}$ & $\begin{array}{l}\text { Surface } \\
\text { Underlying } \\
\text { (1) }\end{array}$ & 8.7 \\
\hline
\end{tabular}

